\title{
Feet, syllables, moras and the Estonian quantity system
} Külli Prillop

University of Tartu

\begin{abstract}
The Estonian language is unique in that it differentiates between three degrees of length in vowels, as well as in consonants. Phonologically, the ternary system of Estonian quantity has been interpreted in a variety of manners, but a generally accepted description has yet to be found. In the present paper, I argue for the approach that overlong segments arise due to foot-final lengthening in monosyllabic feet. Foot-final lengthening is not simply a matter of phonetic implementation. The lengthening may be the result of the addition of a mora at the end of the foot or from the strength of the final mora. I focus my discussion on the second case, which links footfinal lengthening and quantity degrees to the well-known Iambic-Trochaic Law.
\end{abstract}

\section{Introduction}

Estonian is known for its unique quantity system, which distinguishes three quantity degrees: Q1 or short, Q2 or long and Q3 or overlong. Although a widely accepted contemporary view is that Q1, Q2 and Q3 apply to the foot as a whole, I will use the notions that the 'Q1 (or Q2 or Q3) syllable' refers to the stressed (first) syllable of a foot and that the 'Q1 (or Q2 or Q3) segment' refers to the durational contrasts of the individual sounds. Estonian short, long and overlong vowels and consonants yield the following seven possible combinations: ${ }^{1} \mathrm{Q} 1$ u.de 'fuzz', Q2 uu.de 'innovation', Q3 uu:.de 'new, illat.sg.'; Q2 ut.te 'ewe, gen.sg.', Q3 ut:.te 'ewe, part.sg.'; Q2 uut.te 'new, gen.sg.' and Q3 uu.t.te 'innovation, gen.sg.'. ${ }^{2}$ As evident from these examples, contrastive quantity marks differences in both lexical meaning and grammatical function.

This article was written largely as a result of encouragement from Professor Emeritus TiitRein Viitso, who, for a long time, has cherished an interest in the Estonian quantity system (see Viitso 1981, 1997, 2008). Viitso provided the following schematic overview to describe the relationships between Q1, Q2 and Q3:

\footnotetext{
${ }^{1}$ I use the IPA length mark (:) after the lengthened segments to indicate Q3 without distinguishing the extent to which the sound has been lengthened (phonetically, the duration of the $u$ in the word uu:t.te is not equivalent to that of the $u$ in $u u: d e$ or the length of the $t$ to that of the $t$ in $u t: t e$ ). Otherwise, I have abided by the principle of Estonian orthography by using single letters to represent short sounds and double letters to represent long ones (by way of derogation from Estonian orthography, I have also used double letters to represent geminate stops). Dots denote syllable boundaries, and parentheses denote foot boundaries.

${ }^{2}$ These seven example words, which all share the same segmental structure, were originally suggested by Leho Võrk (1966: 34).
} 


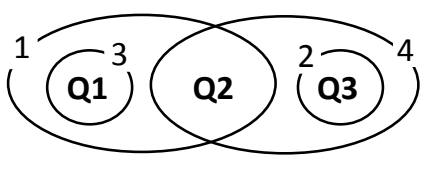

Figure 1. (Viitso 1997: 229, Figure 3) Oval 1 - A Q1 or Q2 syllable is obligatorily followed by one or two unstressed syllables. Oval 2 - A Q3 syllable does not need to be followed by an unstressed syllable. Oval 3 Q1 is associated with light (CV) stressed syllables. Oval $4-$ Q2 and Q3 are associated with heavy (CVV, CVC or longer) stressed syllables.

Phonologically, the ternary system of Estonian quantity has been explained using various means. Almost all of the possible approaches offered by moraic theory and metrical phonology have been used to generate a suitable representation of Q1, Q2 and Q3 feet. Until the mid-20th century, it was widely believed that quantity degrees can be described as segments having three different degrees of length. The currently held view is that quantity degrees derive from the prosodic structure of words.

According to moraic theory, syllables consist of moras. A light syllable is monomoraic, whereas a heavy one is bimoraic. Trimoraic syllables are either unnecessary or extremely rare. Moras also serve as timing units. A short vowel constitutes a single mora, whereas a long vowel constitutes two moras (See Hyman 1985, McCarthy, Prince 1996, Hayes 1989). If a syllable is not allowed to consist of more than two moras, it is impossible to represent trimoraic heterosyllabic vowels. Therefore, the ternary opposition of quantity cannot be treated simply as an opposition between monomoraic, bimoraic and trimoraic segments. For this reason, various amendments have been suggested in moraic theory to allow for a phonological representation of the Estonian quantity degrees, which include the following: freestanding moras, degenerated syllables, monomoraic long vowels, shared moras, etc.

In this article, I consider the pros and cons of these amendments as well as certain other theoretically possible approaches. I refrain from presenting an overview of the historical developments in theoretical approaches to quantity degrees (an excellent one has been provided by Martin Ehala (2003)). The aim of this analysis is to clarify whether modern moraic theory disposes of the theoretical means that allow it to provide an acceptable phonological description of the Estonian quantity system. My hypothesis is that a description that aspires to consistency with regard to the phonetic facts must distinguish between weak and strong moras.

\section{Phonetic properties of Estonian quantity degrees}

According to a widely accepted contemporary view, the domain of Estonian quantity is a disyllabic foot. In terms of their segmental composition, Q1, Q2 and Q3 feet may be identical, yet may exhibit differences in the duration ratios between stressed and unstressed syllables. The Estonian language manifests a phenomenon known as foot isochrony: the shorter the syllable that carries the primary stress, the longer the vowel of the following syllable. Therefore, an unstressed second syllable is the longest in Q1 words and the shortest in Q3 ones (Lehiste 2003: 52). 
The foot-final unstressed vowel in a Q1 foot is typically referred to as half-long. The halflong vowel is a characteristic of Q1 and is best perceived in words pronounced in isolation (Asu, Teras 2009: 370). The unstressed vowel of a Q2 foot may also be half-long (Ariste 1953: 90-91). Unlike Q1 and Q2 feet, Q3 ones tend to exhibit a significant reduction of unstressed vowels. This reduction cannot be explained by the short duration of the unstressed vowels as this duration in Q3 feet and that of the half-long vowels in Q2 feet are sometimes only marginally different. (Eek, Meister 1998, Eek 2008: 101-104)

One possibility is that the duration ratio of the first and second syllable (or of the first and second syllable rhyme) in a foot is the main indicator of Estonian quantity degrees (Lehiste 1960, Liiv 1961; see also objections by Hallap 1962). The typical $\sigma 1 / \sigma 2$ ratio is $2 / 3$ for Q1, 3/2 for Q2 and 2/1 for Q3 (Lehiste 1960, 2003). However, in a perceptual experiment, when listening to monotonous disyllabic nonsense word stimuli, neither Estonian nor American English speakers were able to distinguish the duration ratio of $3 / 2$ from that of $2 / 1$. They were only able to distinguish the short-long (1/2 and 2/3) sequences from the long-short (2/1 and 3/2) sequences (Fox, Lehiste 1989). Moreover, in penta- and hexasyllabic words, the lengthening of the unstressed vowel in Q1 is minimal (Lippus et al. 2006) and depends on the dialectal background of the speaker (Pajusalu et al. 2005).

According to Arvo Eek and Einar Meister (2003, 2004), the duration ratios of syllables are insufficient for distinguishing between quantity degrees. Instead, these authors attribute importance to the duration ratios of the adjacent segments, claiming that listeners are only supposed to assess whether the durations of the adjacent sounds are indistinguishable or one is longer/shorter than the other. For example, the duration ratio in the Q3 word lau:da 'table, part.sg.' for the vowels $u$ and $a$ is 1.4, whereas the corresponding ratio for the Q2 word lauda 'barn, gen.sg.' is 0.8 (Eek, Meister 2003: 818 ff.). Compared to Q2 syllables, only some segments of Q3 syllables are lengthened (see Table 1).

\begin{tabular}{|c|c|c|c|c|}
\hline & \multirow[b]{2}{*}{ Q2 } & \multirow[b]{2}{*}{ Q3 } & \multicolumn{2}{|c|}{ Examples } \\
\hline & & & Q2 & Q3 \\
\hline i. & CVV.CV & CVV:.CV & lau.lu'song, gen.sg.' & lau:.Iu 'song, part.sg.' \\
\hline ii. & CVC.CV & CVC:.CV & par.ve 'raft, gen.sg.' & par..ve 'raft, part.sg.' \\
\hline iii. & CVVT.TV & $\begin{array}{l}\text { CVV:T:.TV } \\
\text { CVVT:TV } \\
\text { CVV:T.TV }\end{array}$ & saat.te 'get, $\mathrm{pl2'}$ & saa:t:.te 'broadcast, gen.sg.' \\
\hline iv. & CVNT.TV & CVNT:.TV & ärt.tu 'hearts, nom.sg.' & part:.ti 'duck, part.sg.' \\
\hline v. & CVVN.TV & CVV:N.TV & kaar.di'map, gen.sg.' & kaa:r.du 'curved' \\
\hline vi. & CVVNT.TV & $\begin{array}{l}\text { CVV:NT:.TV } \\
\text { CVVNT:.TV } \\
\text { CVV:NT.TV }\end{array}$ & kaart.te 'arc, gen.pl.' & kaa:rt:.te 'map, part.pl.' \\
\hline
\end{tabular}

Table 1. (C - consonant, $\mathrm{V}$ - vowel, $\mathrm{T}$ - obstruent, $\mathrm{N}$ - sonorant)

The Q3 sequences presented in rows iii and vi of Table 1 are subject to dispute. Ilse Lehiste (1965: 452) does not regard sequences CVVT:.TV and CVV:T.TV as possible. Judging by a 
transcription made by Tiit-Rein Viitso (2008: 176), he believes that lengthening can apply to both the vowel and the stop or to just the vowel. Using similar example words, Mati Hint (1998: 110) marked stops rather than vowels as the Q3 centres. The measurements conducted by Arvo Eek and Einar Meister (2004: 270) showed that the VV preceding a stop in these word types had a duration that was indistinguishable in Q2 and Q3. No similar measurements were performed for the sequence CVVNT.TV. Most probably, the pronunciation of the sequences CVVTTV and CVVNTTV depends on the speaker.

In addition to durational differences, a crucial factor for determining the degree of quantity is the pitch pattern. Q2 feet all have a relatively high, level pitch on the first syllable, and a low one on the second, whereas Q3 feet exhibit a pitch fall on the first syllable, which is followed by a low pitch on the second syllable. The Q1 pitch pattern is similar to that of Q2 (Lehiste 2003: 52). Perceptual tests suggest that, in the absence of the correct pitch pattern, Q3 remains imperceptible. However, when the pitch cue is missing (in the case of CVT.TV sequences), all of the quantity degrees are perceived according to the temporal structure of the stimuli (Lippus et al. 2007, 2009).

Researchers have also investigated quality differences between short, long and overlong stressed vowels. Short stressed vowels are the most centralised and overlong vowels are the most peripheral, but in Standard Estonian these differences are not sufficient for long and short vowels to be treated as different phonemes (Eek 2008: 99-101). In spontaneous speech, the quality differences between short and long vowels are considerably larger than those found in lab speech (Lippus 2010).

\section{Ternary length contrast of vowels}

Ternary length contrasts are rare cross-linguistically. For the vast majority of languages that supposedly have three contrastive lengths, the methods of phonological analysis that have been used or are still being developed do not inevitably require overlong (trimoraic) vowels in addition to the short (monomoraic) and long (bimoraic) ones. Differences in phonetic duration may reflect multiple phonological phenomena.

For instance, consider the Low German ternary length opposition that results primarily from pitch differences between long and overlong vowels in certain dialects (Gussenhoven, Peters 2004) and from quality differences (tense vs. lax) between short and so-called long vowels in other dialects (Kohler 2001). In principle, a similar solution could be conceivable for Estonian, as the perceptual tests conducted by Lippus, Pajusalu and Allik (2007, 2009) show that Q3 is not perceived unambiguously without the falling pitch. Yet, there is no pitch cue in CVT.TV words. Thus, such an account would only cover a portion of the differences between Q2 and Q3 words in Estonian. It would also mean that morphologically induced changes in quantity degrees could not be described as a single phenomenon. Rather, they would depend on the segmental composition of the words. For instance, to form the genitive par.ve of the word par:v 'raft' one would need to 
replace the falling pitch with a level one, whereas the genitive kok.ka of the word kok:k 'cook' cannot be formed in the same manner.

In Applecross Gaelic, the ternary opposition of vowels is only manifested in monosyllabic words, whereas disyllabic ones do not allow overlength. For instance, in the case of adding the suffix /-ən/ to a word that contains an overlong vowel, the vowel is shortened, cf. [su::1] 'eye' [su:lən] (Ternes 1989: 102-110). According to an analysis by Norval Smith (2004), the true members of the opposition are long vowels and sequences of identical heterosyllabic vowels. In diachronic terms, the overlength of Gaelic vowels results from the loss of the intervocalic consonant. Speakers of contemporary Gaelic perceive the relevant words as disyllabic ones (Smith 2004). Here, a parallel to Estonian may also be discerned, as it has a considerable number of Q3 words that have appeared relatively recently as a result of the loss of an intervocalic stop. In fact, this stop may still be present in certain morphological forms of the word, cf. (disyllabic) ka.du 'loss, nom.sg.' and (monosyllabic) kao: 'loss, gen.sg.'. Yet, this does not explain Q3 in words such as par:.ve 'raft, part.sg.' or kat:.ta 'to cover', which do not include a diphthong straddling a syllable boundary.

Ternary length contrasts can also be analysed by means of shared moras, provided that the structure shown in Figure 2 is interpreted such that a segment in a shared mora is shorter than a corresponding fully moraic segment.

\section{a. shared mora b. unshared moras}

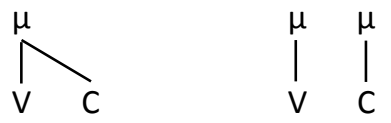

Figure 2.

The necessity of mora sharing for describing phonological systems has been highlighted by Ian Maddieson (1993), Bruce Hayes (1989, 1995: 337-338), Ellen Broselow, Su-I Chen, Marie Huffman (1997) and Janet C. E. Watson (2007) among others. This analysis may even be suitable for Dinka. In Dinka, almost all of the words are monosyllabic, but Dinka has rich morphology that alters the length, pitch, voice quality and/or final consonant of the words (Andersen 1992-1994, Remijsen, Gilley 2008). Remijsen and Gilley (2008: 340, 334-335) note that VVV sequences are not three times the length of $\mathrm{V}$, as they only amount to double the length of $\mathrm{V}$, and when the duration of the vowel increases, the duration of the coda decreases slightly (elision of the coda is most probable after VVV). One possibility for representing a ternary length opposition through shared moras is shown in Figure 3. In this case, the durations of $\mathrm{V}$ and $\mathrm{C}$ are interrelated.

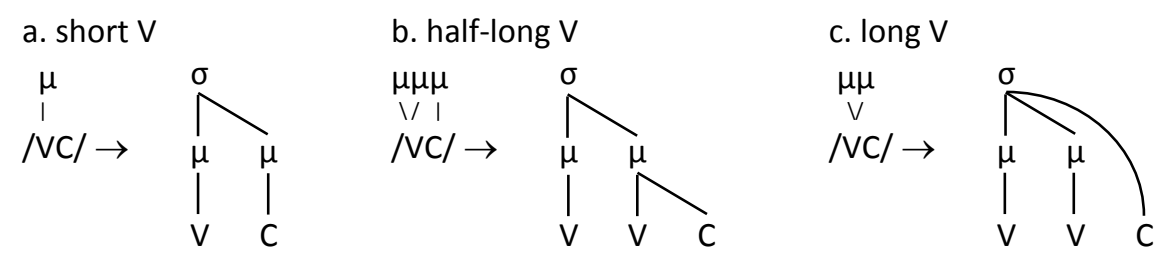

Figure 3. 
This interpretation of ternary opposition is clearly unacceptable for Estonian, given that in Estonian words, such as Q2 öö.bik 'nightingale' and Q3 öö..bib 'stay overnight, sg3.', the initial syllable has no onset or coda that the vowel can share a mora with.

\section{Ternary length contrast of consonants}

In most cases, the difference in the length of consonants is revealed when the consonants occur intervocalically, i.e., the opposition involves single consonants and geminates. The only known languages other than Estonian that have a ternary length opposition of the consonants independent of the length of the preceding/following vowel are Saamic (see Bye, Sagulin, Toivonen 2009, and the references therein).

In moraic theory, a geminate is defined as an underlying moraic consonant (Hayes 1989). In output forms, however, long and short geminates can still be distinguished (Figure 4). In the input, both short and long geminates are moraic (Davis 2003). Theoretically, shared moras may also occur in the input, which would allow underlying ternary length oppositions. Yet, as I explained in the previous chapter, this does not aid in providing a description of the Estonian quantity system, which allows vowel and consonant lengths to be combined independent of each other.

a. single $C$

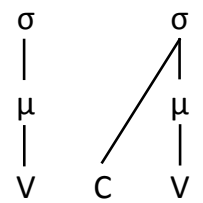

b. short geminate

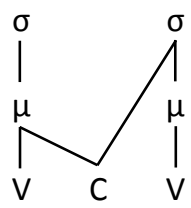

c. long geminate

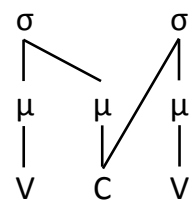

Figure 4.

In the input, one may hypothesise the occurrence of a sequence of two identical consonants (the so-called fake geminate), which would generate a short geminate (as in Figure 4b) as its output form or a nonmoraic geminate. Stuart Davis (2003) concluded that, within a morpheme (or, more generally, in underived environments), one does not need to hypothesise the occurrence of a sequence of identical consonants in the place of a geminate. However, he did not extend his analysis to cover Finnic or Saamic languages.

Estonian permits sequences of identical consonants at morpheme boundaries, including sequences that arise when a clitic, such as $-k i$, is added to a word ending in $k$. Unlike stem-internal geminates, in sequences of identical consonants the $-k i$ starts with an implosion and the preceding $k$ ends with an explosion (see Ariste 1953: 95). C.C vs. $C_{\mu}$ (or $C_{\mu} \cdot C$ ) is not a suitable method for distinguishing the three different degrees of consonant length in Estonian stems. Even if it were acceptable, it would be of little help in the search for a uniform approach that is applicable to the quantity degrees of both vowels and consonants. 


\section{Moraic theory-based analysis of Estonian quantity degrees without trimoraic segments}

To avoid trimoraic segments, short, long and overlong vowels must be accommodated in what is at most a bimoraic space. One option would be to postulate that both Q1 and Q2 syllables are monomoraic, whereas Q3 ones are bimoraic. This view has been adopted by Mati Hint (1997, 2001) and Martin Ehala (1999, 2003). If Q3 syllables were heavy and all of the other syllables were light, it would be easy to explain why in Estonian only Q3 syllables may be directly followed by a secondary-stressed syllable, given that only a bimoraic syllable (and never a monomoraic one) could function as a separate foot.

If Q1 and Q2 syllables are monomoraic, this would mean that short and long vowels are also monomoraic, cf., the $a$ in the words (Q1) a.bi 'help' and (Q2) aa.bits 'ABC', and we would need to account for the difference that is apparent between these examples. Mati Hint (2001: 257) suggests that a correct analysis of Estonian long phonemes should treat them as sequences of two identical phonemes, yet he does not provide the corresponding prosodic trees. Hint also stresses the fact that Estonian does not use an opposition between short and long segmental phonemes (2001: 257), although moraic theory does not recognise the segmental feature [ \pm long]. Any vowel phoneme is short if it is linked to one mora and long if it is linked to two moras. The adjacent occurrence of two identical phonemes is prevented by the universal Obligatory Contour Principle (OCP), which states that adjacent identical elements are prohibited at the melodic level (see McCarthy 1986).

Moraic theory does not encounter difficulty when describing the fact that, in minimal pairs, the first and second elements of long monophthongs are replaceable with other vowels and the second element is replaceable with a consonant. Therefore, in terms of structure, the first element of a long vowel can be interpreted as the syllable nucleus and the second element as the coda (the argument advanced by Eek and Meister (2003: 832) for treating long vowels as biphonemic). Moraic theory does not need to distinguish between nucleus and coda in syllable structure; rather, the property that matters is the number of moras in a syllable, cf., a heavy syllable in moraic theory (Figure 5a) and its predecessor, a syllable with a branching rhyme (Figure 5b) (for details, see, for instance, Zec 2007).

a.

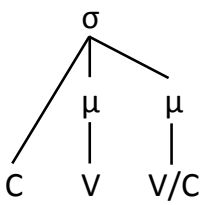

b.

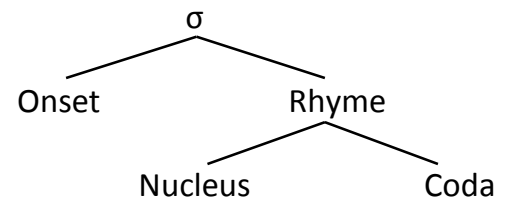

Figure 5.

Estonian is not the only language in respect of which it has been suggested that the long vowel is really a sequence of two identical vowels. In Chapter 3, I mentioned Applecross Gaelic, in which these vowels are considered as belonging to different syllables, unlike the solution proposed regarding Estonian by Hint. Nicholas Rolle (2009) argues for this approach with regard to the 
Niuean language, in which underlying identical vowel-vowel sequences surface as a long vowel if the stress falls on the first vowel of this sequence and as a double articulated heterosyllabic vowel if the stress falls on the second vowel. Thus, there is no sequence of identical vowels within the same syllable in Niuean.

To allow for monomoraic long vowels, Martin Ehala (2003: 73-75) inserted an additional level in the prosodic tree, which may be depicted as in Figure 6. Ehala (2003: 74) traces this representation to the hypothesis formulated by Bruce Hayes (1995: 299-301), which argues that moras of different levels could be used to describe a language that treats CVC as heavy for some distinctions but light for others.

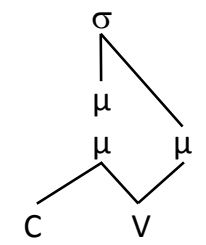

Figure 6.

In his model, Hayes formulated a rule that states that "in two-layer systems, the heights of moraic columns are persistently adjusted to conform to the sonority of the segments that license them" (Hayes 1995: 300). Hence, the structure shown in Figure 6 is inevitably transformed into the structure shown in Figure $7 \mathrm{~b}$. Were this not the case, the loss of a coda linked to a mora would normally lead to monomoraic instead of bimoraic long vowels.

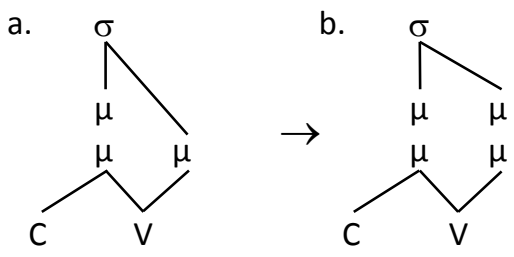

Figure 7.

A representation of this type, which involves an extra level, is not markedly different from approaches that combine moraic theory and X-slot theory and posit the existence of different levels for moras (which determine the weight of a syllable) and X-slots (which determine the length of a segment) in the phonological tree (for instance, see Lahiri, Koreman 1988). This approach was required for Dutch as it also was claimed to manifest monomoraic long vowels. Yet, it was subsequently shown by Carlos Gussenhoven (2009) that in Dutch, too, there is no need for monomoraic long vowels. The problematic tense vowels in question acquire their second mora when they appear in a stressed position, while retaining their underlying monomoraicity in unstressed positions, in which they traditionally have been regarded as long.

Vowels can have no more than two moras also when Q1 is regarded as monomoraic and Q2 and Q3 as bimoraic. This type of analysis was suggested by Arvo Eek and Einar Meister (2004: $351 \mathrm{ff}$.), who believed that the difference between Q2 and Q3 was that the syllable nucleus shares a mora with the coda in Q3, whereas this is not the case in Q2 (Figure 8). (They also treated the 
second element of a diphthong and the end part of a long vowel as the syllable coda (Eek, Meister 2004: 833).)

a. Q2

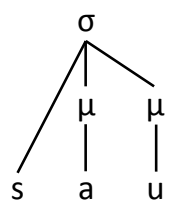

'sauna, gen.sg.' b. Q3

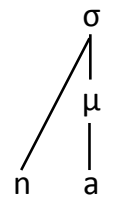

s.'

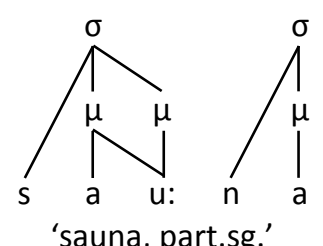

'sauna, part.sg.'

Figure 8. (Eek, Meister 2004: 352)

This representation is problematic for words that contain a long vowel. Sharing the first mora in Q3 syllables may result in perceptible differences with regard to dipthongs, whereas, this is questionable with regard to long vowels (see Figure 9). Essentially, words like Q3 saa:ma 'get' would still require a trimoraic vowel.

a. Q2

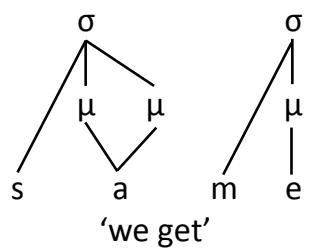

b. ? Q3

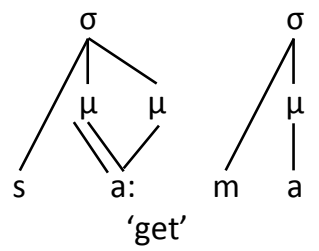

Figure 9.

Eek and Meister (2003: 833-834) argue that the long vowel is a sequence of two identical vowels, and that the boundary between the adjacent identical vowels is determined by the $F_{0}$ peak, which is located in the second half of the vowel for Q2 and in the first half for Q3. However, as shown with acoustic measurements, the location of the $\mathrm{F}_{0}$ peak is not a sufficiently reliable marker of the boundary between identical vowels (Eek 2008: 57). In addition, as I noted regarding Hint's treatment of quantity degrees, sequences of two identical tautosyllabic phonemes would violate the OCP and be unique to Estonian.

Another problem relates to the duration of sounds, which Eek and Meister's representations should reflect with considerable precision given their contention that the difference between Q2 and Q3 lies in mora sharing between the nucleus and the coda. The results of measurements performed by Eek and Meister (2004: 270) show that the average duration of the first $a$ in the Q2 word lau.da 'barn, gen.sg.' is $96 \mathrm{~ms}$ and the average duration for the $u$ in the same word is $76 \mathrm{~ms}$, whereas the corresponding values in the Q3 word lau:da 'table, part.sg.' are 108 ms and $143 \mathrm{~ms}$. Eek and Meister's representation is a good match for these durations in that the duration of the constituent elements of the diphthong is more or less equal in Q2 and the duration of the $u$ is considerably longer in Q3. However, their representation also suggests that the $a$ in Q3 should be shortened to the same extent that the $u$ is lengthened, and that the total duration of the diphthong should remain the same in Q2 and Q3. The representational trees drawn by Eek and Meister also fail to explain the reduction of the final vowel in the Q3 foot given that a similar reduction is absent in $\mathrm{Q} 2$. 
No satisfactory description using a maximum of two moras has been offered to date for the ternary length opposition in Estonian. To provide an acceptable description, either a third mora has to be added, or there must be an admission that the opposition is more than just a contrast in length.

\section{Weak layering and maximal binarity}

Renouncing trimoraic vowels and bimoraic consonants does not automatically mean giving up trimoraic or so-called superheavy syllables. Similarly, a prohibition of superheavy syllables does not entail a prohibition of trimoraic vowels. One or both of these two options may be necessary to provide a description of the Estonian quantity degrees.

Trimoraic syllables are prohibited by the requirement of maximal binarity that applies to phonological constituents. If extrasyllabic moras are allowed, this requirement would not interfere with the existence of trimoraic vowels (Figure 10).

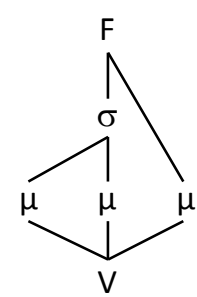

Figure 10.

According to moraic theory, one way that superheavy syllables are formed is when a long vowel is followed by a geminate (Figure 11a). If mora sharing is allowed, this syllable could also be bimoraic (Figure 11b).

a.

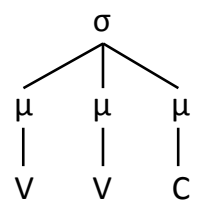

b.

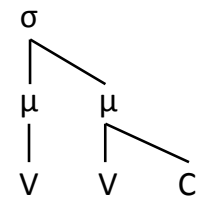

Figure 11.

Certain languages have a stress system that signals the existence of trimoraic syllables. In Hindi, the word stress falls on the heaviest syllable of the word, and CVVC is heavier than bimoraic CVV (Hayes 1989: 291). In Arabic dialects, word-final syllables carry stress if they are superheavy (Hayes 1995: 67, 226). Evidence of the existence of trimoraic syllables may also be found in the verse systems of languages and in cases of compensatory lengthening of heavy syllables (Hayes 1989: 291-197).

Cross-linguistically, superheavy syllables have a common property in that they are not allowed to appear in a weak branch of the foot. Therefore, trimoraic syllables are stressed (except when a particular language allows the existence of feet that do not contain a stressed syllable, such as Hindi, cf., Hayes 1995: 165, 277). This phenomenon is difficult to justify when the three moras of a superheavy syllable are linked to the syllable node in the same way as the two moras of a heavy syllable are linked to the syllable node. 
In the development of the Prosodic Hierarchy Theory an important role was played by the Strict Layer Hypothesis formulated by Elisabeth Selkirk: "A category of level $i$ in the hierarchy immediately dominates a (sequence of) categories of level $i-1$ " (Selkirk 1984: 26). The contemporary version of the theory also allows weak layering, including extrasyllabic consonants, unparsed syllables and semisyllables (i.e., moras that are unaffiliated with syllables and linked to higher-level prosodic constituents). It is, however, unclear which constituents can remain without a link to next level constituents and how many levels can be skipped in this way (see, for instance, Ito, Mester 2003, Kiparsky 2003, Vaux, Wolfe 2009.)

According to Junko Ito and Armin Mester (2003: 15), all of the prosodic words shown in Figure 12 are equally allowed. For instance, an F-structure (12a) in Estonian is (ka.la) 'fish', an FF-structure (12b) is (ka.la).(de.le) 'fish, all.pl.' and an Fo-structure (12c) is (ka.la).le 'fish, all.sg.' . Ito and Mester (2003: 11) also claim that a mora must be affiliated with a syllable. Paul Kiparsky (2003: 153-156) finds that neither the segment nor the mora have to be affiliated with a syllable, but either may be directly linked to a prosodic word. Bert Vaux and Andrew Wolfe (2009) argue that the choice of the node to which elements (they only analysed segments) are linked varies both within and across languages.
a. $\left.\quad\right|_{F} ^{\omega}$
b.
c.

Figure 12 .

If the structure of phonological constituents is by and large identical across all levels, then, in addition to the prosodic words shown in Figure 12, feet should also be allowed to have an analogous structure (shown in Figure 13).
a. $\quad{ }_{\sigma}$
b. $\overbrace{\sigma}$
c. $\overbrace{\sigma}$

Figure 13.

A central claim of metrical phonology is that feet are maximally binary-branching (Hayes 1995, Kager 1993 and others). The requirement of maximal binarity rules out $\sigma \mu$-sequences in the weak branch of the foot, because this foot would be ternary-branching (Figure 14, improper structures are marked with an asterisk).

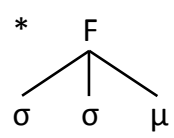

Figure 14.

Yet, this does not rule out unstressed $\sigma \mu$-sequences in word-final positions, as shown in Figure 15. These sequences could be avoided if the number of levels that can be skipped is limited to one. If the mora does not belong to a syllable, then it must belong to the foot, and if the syllable does not belong to a foot, then it must belong to the prosodic word. Weak layering, when restricted 
in this manner, rules out the monosyllabic words containing quadrimoraic (or even longer) vowels, as shown in Figure 16.

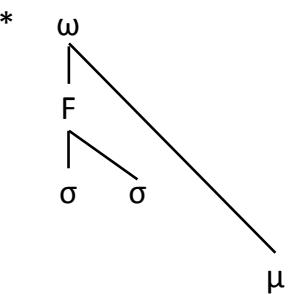

Figure 15.

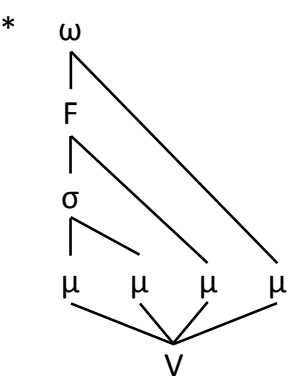

Figure 16.

An interesting question is whether maximal binarity only applies to the foot. Prosodic words should also be maximally binary. This would mean that pentasyllabic and longer morphologically complex words contain recursive prosodic words, such as, [[(ka.va).la.][(ma.te.).le]] 'smart, all.pl.' in Estonian (cf., Kager 1997).

Segments as a category are qualitatively different from moras, syllables and prosodic words. They can be divided between different constituents, whereas a mora is never ambisyllabic and a syllable never divides between two feet (Nespor, Vogel 1986: 7). Segments can divide between two syllables. In addition, three segments may be linked to one mora, and nonmoraic consonants may be directly linked to bimoraic syllables (cf., Vaux, Wolfe 2009).

The possibility of resorting to extrasyllabic moras to provide a description of the Estonian (and Saamic) quantity degrees was first discussed by Patrik Bye (1997). In his analysis, the third mora is a freestanding one or belongs to a degenerate syllable (Figure 17). Bye argues that his analysis accounts for variations such as (kau:).(ge.le) (kau:.ge).le 'far'. In the first variation, the centre of Q3 is a degenerate syllable, i.e., kau formally functions as a disyllabic unit followed by a secondary-stressed foot. In the second variation, the centre of Q3 is a free mora and kau is the initial syllable of a disyllabic foot (Bye 1997: 53-55).
a. Q3 $=\sigma_{\mu \mu}+\sigma_{\mu}{ }^{\text {egen }}$
b. $\mathrm{Q} 3=\sigma_{\mu \mu}+\mu$
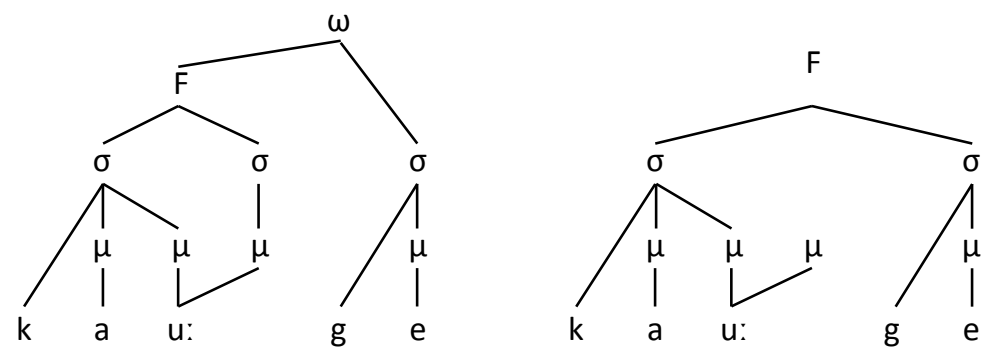

Figure 17. (Q3 according to Bye 1997) 
A similar approach to quantity degrees was suggested by Eek and Meister (2004: 352), who argued that Q3 could either be an ordinary syllable plus a degenerate syllable that together form a separate foot or an initial bimoraic syllable of a disyllabic foot in which the nucleus and the coda suitably participate in mora sharing, as described in the previous chapter. Eek and Meister's double presentation of Q3 also aims to explain why, in some cases, a Q3 syllable may be followed directly by a secondary-stressed one.

According to the current version of the Prosodic Hierarchy Theory, it is not necessary to present Q3 feet in two different ways in order to account for this phenomenon. Removal of the third mora from the syllable (Figure 13c) does not mean that the trimoraic foot, which is formed as a consequence of this operation, needs to be directly followed by a secondary-stressed syllable. In the case of weak layering, foot-external syllables are allowed (Figure 12c).

Whether a Q3 foot is followed by a secondary-stressed syllable depends on whether the language allows adjacent stressed syllables (stress clash) or unparsed syllables. This difference is extremely easy to show in Optimality Theoretic phonology given that output forms are determined by a language-specific hierarchy of universal, yet violable constraints (Prince, Smolensky 2004), as follows:

* $\sigma$-ClASH $\quad$ No stressed syllables are adjacent (in a prosodic word) (Kager 1999: 165).

PARSE- $\sigma \quad$ Syllables are parsed by feet (Kager 1999: 153).

\begin{tabular}{|c|c|c|}
\hline /kauge+le/ 'far' & ${ }^{*} \sigma$-CLASH & PARSE- $\sigma$ \\
\hline \hline (kau:).(ge.le) & ${ }^{*} !$ & \\
\hline (kau:).ge.le & & ${ }^{* *}$ \\
\hline \hline /kauge+le/ 'far' & PARSE- $\sigma$ & ${ }^{*} \sigma$-CLASH \\
\hline \hline \multirow{2}{*}{ (kau:).(ge.le) } & & ${ }^{*}$ \\
\hline (kau:).ge.le & ${ }^{*} ! *$ & \\
\hline
\end{tabular}

Table 2.

It is unclear how these two unparsed syllables should be shown in a strict binary tree (if the requirement of strict binarity also applies to the prosodic word level). The version of weak layering described here requires unparsed syllables to belong to prosodic words, but does not prescribe the number of the level whose recursive prosodic words they must be affiliated with. Hence, the structure shown in Figure 18 appears to be suitable. (An alternative would be a foot without a stressed syllable.) Unlimited insertion of syllables unparsed by feet into a word, as shown in Figure 19 , is prevented by the constraint PARSE- $\sigma$ (see Table 3 ). 


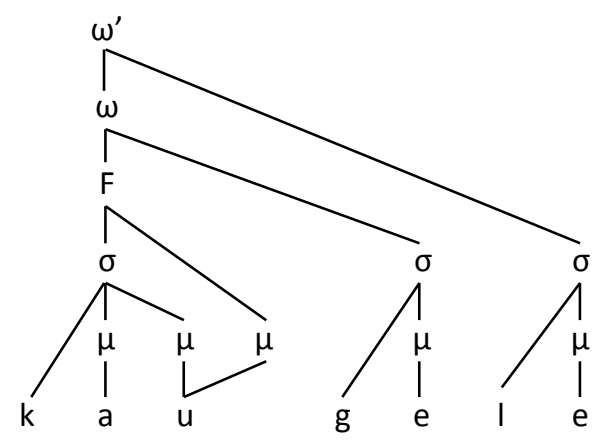

Figure 18.

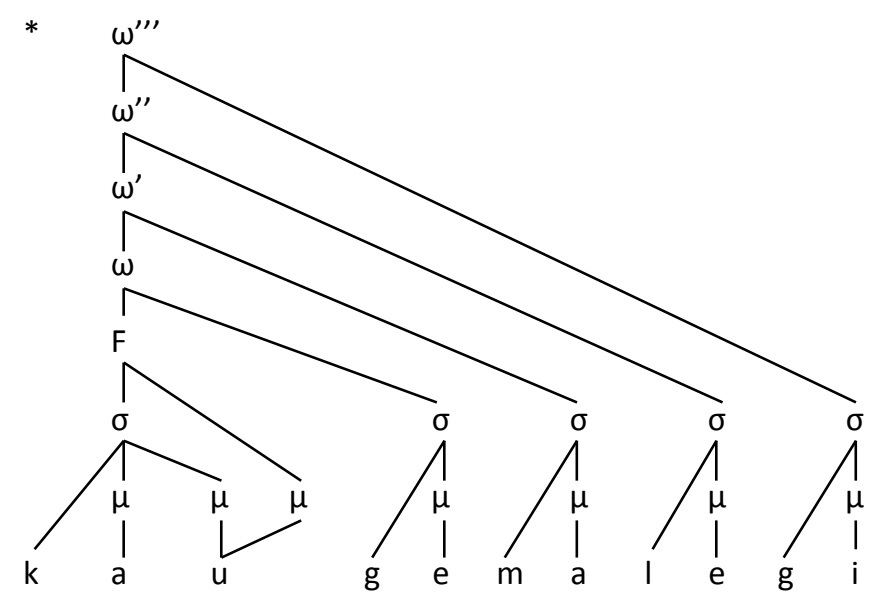

Figure 19.

\begin{tabular}{|c||c|c|}
\hline $\begin{array}{l}\text { /kauge+ma+le+gi/ } \\
\text { 'even further' }\end{array}$ & $* \sigma$-CLASH & PARSE- $\sigma$ \\
\hline \hline (kau:).ge.ma.le.gi & & $* * * !^{*}$ \\
\hline (kau:).(ge.ma).(le.gi) & $* !$ & \\
\hline (kau:).ge.(ma.le).gi & & $* *$ \\
\hline
\end{tabular}

Table 3.

If phonological constituents are maximally binary and only one level can be skipped when linking them, then any trimoraic Q3 syllable-mora sequence constitutes a separate foot. The acceptability of this approach with regard to the quantity degrees depends on whether trimoraic vowels are allowed, i.e., whether, in spite of the arguments presented in Chapter 3, they are required for languages other than Estonian. Due to the principles discussed previously, the maximal number of moras that a tautosyllabic long vowel is allowed to have is three. The addition of a fourth mora, as shown in Figure 20, is not possible without the addition of a second syllable, given that linking a fourth mora to the foot would make the foot ternary and linking it to the prosodic word would mean skipping two levels. 


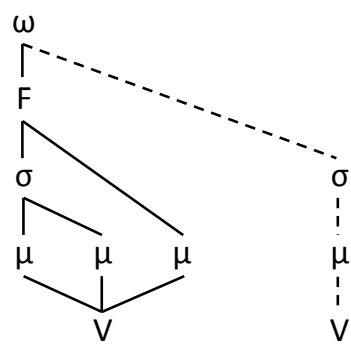

Figure 20 .

\section{Q3 and foot-final lengthening}

In 1980, Alan Prince suggested that Q3 constitutes a separate foot. Prince's analysis based on an early version of metrical phonology. His main idea was that the lengthening of Q3 syllables compared to Q2 syllables was a result of foot-final lengthening, similar to how the lengthening of the end vowel of a Q1 foot results from foot-final lengthening. The same idea was used by Paul Kiparsky and Karl Pajusalu (in preparation, see also Pajusalu 2002), who argued that foot-final lengthening maximizes the duration of the weak branch of a foot, in satisfaction of PEAK-TOWeight. PEAK-TO-WeIGHT is a constraint that is analogous to the widely used STRESS-TOWEIGHT constraint (which requires stressed syllables to be bimoraic) and requires primary-stressed feet to be trimoraic (Kiparsky, Pajusalu, in preparation). As such, PEAK-TO-WeIGHT does not allow foot-final lengthening in secondary-stressed feet. Yet, at least in West Saaremaa Estonian, lengthening has been recorded in secondary-stressed feet (Pajusalu et al.).

An important difference between the approaches of Prince (1980) and of Kiparsky and Pajusalu (2002) is that Prince believes that foot-final lengthening is simply a matter of phonetic implementation, whereas Kiparsky and Pajusalu believe that the lengthening is phonological. If foot-final lengthening is merely a phonetic phenomenon and the only difference between Q2 and Q3 is their different footing, it would be difficult to formulate morphological rules that change the quantity degree of words. For instance, the marker of the partitive case in various word types should be the particular structure of that word type as opposed to the mere possession of an additional mora.

As noted by Kiparsky and Pajusalu (in preparation), the feature of Seto Estonian that allows final lengthening to be realised as the gemination of $/ \mathrm{h} /$ in cases in which the final vowel of the foot is followed by an intervocalic /h/, e.g., /kupõhitõ/ > (ku.põh).(hi.tõ) 'of the sides', cannot be explained by phonetic lengthening.

To satisfy the PEAK-TO-WEIGHT constraint, lengthening in Standard Estonian is applied to the vowel in the second syllable of the foot, given that adding a mora to a vowel in the initial syllable or to a consonant would obscure lexical contrasts (Kiparsky, Pajusalu, in preparation, Pajusalu 2002).

Second-mora lengthening occurs in many Finnish dialects as well. It may cause problems in distinguishing the distinctive vowel lengths in unstressed syllables, cf., kala 'fish, nom.sg.' and kalaa 'fish, part.sg.'. Distinctions between these words are maintained with the help of differences 
in pitch contours (Eek, Meister 2004: 343). In Northern Finnish, the difference between a secondsyllable single short (lengthened) vowel and a long vowel after a light initial syllable is rather precarious. For example, the VV/V durational ratio measured in (CV.CVV).CV and (CV.CV).CV nonsense items was 1.5. (Suomi, Meister, Ylitalo, Meister 2013: 11) If, in Finnish dialects, footfinal lengthening obscures the lexical contrasts, then the retention of contrasts could not be regarded as a general ban on such lengthening. On the other hand, if foot-final lengthening does not obscure the lexical contrasts, then it could not constitute a mora addition. All bimoraic vowels in the output should have the same duration, regardless of whether the second mora is lexical or acquired. Lengthening-induced neutralisation of lexical contrasts evokes an interesting fact from languages with iambic rhythm. In iambic languages, as a rule, the second (i.e., stressed) vowel of the foot is lengthened, whereas the lengthened short vowel tends to not be merged with an underlying long vowel (Hayes 1995: 269).

Objections to final lengthening as the addition of a mora can also be found in Estonian morphology. For instance, forms, such as *(mõ.ruid), that contain a bimoraic unstressed syllable are considered ungrammatical, whereas those with a foot-final lengthened bimoraic vowel, such as (mõ.ru) 'bitter', are grammatical. A possible solution to this problem is cyclic derivation.

Foot-final lengthening that serves as the addition of a mora is not entirely uncontested, so it is sensible to continue looking for other options. Leaving for the time being the issue of whether foot-final lengthening constitutes as the addition of a mora or as something else open, Estonian quantity degrees can be represented by the following schematics (foot-final lengthening is indicated by '+'): 
Q1

Q1
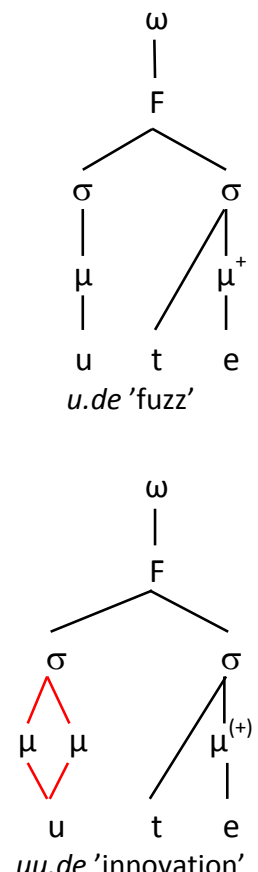

Q3
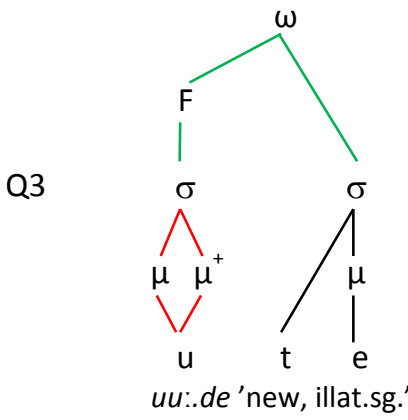

uu:.de 'new, illat.sg.'

Q2
Q2
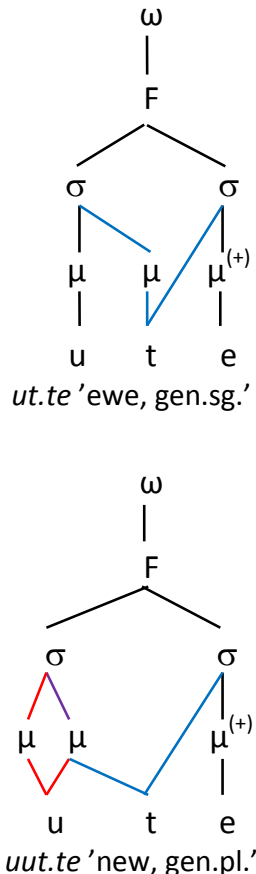

Q3

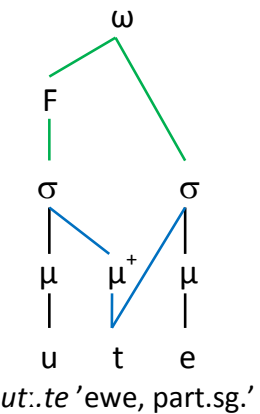

Figure 21

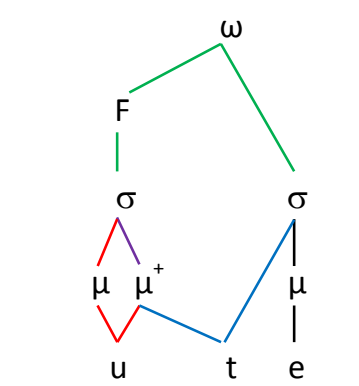

uu:t:.te'innovation, gen.sg.'

\section{Strong and weak moras}

Next, I will deal with another possible account of foot-final lengthening, which is based on the assumption that the phonological constituents of the various levels are uniform in their structure and ties final lengthening to the Iambic-Trochaic Law (below, 'the ITL'). Bruce Hayes (1995: 79-80) describes experiments in which subjects are asked to listen to synthesised sounds played at a regular rhythm. In some sound sequences, every other sound is louder, whereas in others, every other sound is longer. Listeners are asked to judge how the sounds are most appropriately grouped in pairs. The typical result for experiments like this is that for intensity contrasts, subjects prefer groupings with the most prominent element first, whereas for durational contrasts, subjects prefer groupings with the most prominent element last. Hayes formulated these results as the ITL:

Iambic/Trochaic Law (Hayes 1995: 80)

a. Elements contrasting in intensity naturally form groupings with initial prominence.

b. Elements contrasting in duration naturally form groupings with final prominence. 
Across stress systems, ITL is manifested such that trochaic feet are formed preferably from units (i.e., syllables or moras) of the same duration, whereas iambic feet are formed from units of different duration (Hayes 1995: 82), as follows:

$\begin{array}{ll}\text { Syllabic trochee } & (\dot{\sigma} \sigma) \\ \text { Moraic trochee } & \left(\dot{\sigma}_{\mu} \sigma_{\mu}\right) \text { or }\left(\dot{\sigma}_{\mu \mu}\right) \\ \text { Iamb } & \left(\sigma_{\mu} \dot{\sigma}_{\mu \mu}\right)\end{array}$

In addition, Hayes notes that in languages that exhibit iambic rhythm, the lengthening of the vowel of the stressed syllable or the gemination of the coda consonant is a typical phenomenon, whereas this is not the case in languages that exhibit moraic trochaic rhythm. The lengthening of the stressed syllable occurs in syllabic trochaic languages (Hayes 1995: 83-84).

René Kager (1992, 1993, 1999: 171-175) has shown that the asymmetry of iambs and trochees can be described without invoking the ITL. According to Kager, languages with stress systems that are weight-sensitive are characterised by a rhythm that is based on the alternation of strong and weak moras. The first mora of a long syllable, which is linked to the syllable nucleus, is more sonorous than the second mora, which is linked to the coda. Therefore, the first mora may be considered strong and the second one is weak. The mora of a short syllable is strong if the syllable is stressed; if not, it is weak. Kager suggests that every foot must end with a strong-weak sequence. This allows a simple explanation to be advanced for the fact that iambic languages universally prefer unbalanced feet $\left(\sigma_{\mu} \dot{\sigma}_{\mu \mu}\right)$ to balanced ones $\left(\sigma_{\mu} \dot{\sigma}_{\mu}\right)$, whereas the opposite is evident in moraic trochaic languages, which prefer balanced $\left(\dot{\sigma}_{\mu} \sigma_{\mu}\right)$ feet to unbalanced ones $\left(\dot{\sigma}_{\mu \mu} \sigma_{\mu}\right)$.

According to Kager's approach, mora strength is determined by the location of the mora in the prosodic tree. In an earlier theory, stress was also determined by the location of the syllable in the tree. Stress was assigned to the head syllable of a metrical foot. There are still languages, like Cairene Arabic, that refer to the maximally parsed foot structure to locate the primary stress, yet they do not recognise secondary stress. A number of Optimality Theoretic approaches (e.g., Crowhurst 1996) have abandoned the assumption that heads are primitive elements of metrical feet. In this view, the presence of metrical heads within feet is enforced by constraints, as are other aspects of phonological representation. Constraints that require metrical headship may be violated when conflicting constraints have priority (Crowhurst 1996: 411).

If stress is located in accordance with the hierarchy of violable constraints or can be absent altogether, then, assuming that constituents of different levels (above segments) are largely identical in their structure, the location of strong moras should also be determined by the violable constraints. There should be nothing requiring that, for all cases and languages, the first mora of a heavy syllable is strong. The location of stress depends on the weight of the syllable, the sonority of the syllable nucleus, the position of the syllable in the foot, and so on. The position of the strong mora could also depend on the sonority of the segment, the position of the segment in the syllable 
or the foot, and so on. If Kager's assumption that the first mora of every long syllable and stressed light syllable is a strong one and all other moras are weak is ignored, then another explanation is needed to account for the asymmetry of iambs and trochees.

The phenomenon underlying the ITL — in the case of a difference in the intensity of sounds, preference is given to groups in which the first element is prominent, whereas in the case of a difference in the duration of sounds, preference is given to groups in which the last element is prominent-fits well with the replacement of the parametric constraints TROCHEE and IAMB with the corresponding non-parametric constraints, as follows:

TROCHEE The first syllable of every foot is a prominent one.

IAMB The last mora of every foot is a prominent one.

The generation of a language with iambic rhythm requires the following additional constraint:

\section{$\mu^{+} / \sigma \quad$ Every strong mora belongs to a stressed syllable.}

The constraint $\mu^{+} / \sigma$ is analogous to other constraints that require prominent elements (such as sonorous or long vowels) to be stressed.

A possible drawback of this approach is that it rules out languages with iambic rhythm in which the second syllable of the foot does not contain a strong mora. According to Hayes (1995: 269), iambic lengthening is not obligatory. I suppose that the phonetic realisation of a strong mora may vary widely in terms of duration, similar to how the phonetic realisation of stress is not the same across languages. Strong and weak moras cannot create lexical length contrasts. This is important in order to avoid unattested lexical length oppositions, such as $V_{\mu}$ vs. $V_{\mu^{+}}$vs. $V_{\mu \mu}$ vs. $\mathrm{V}_{\mu \mu+}$, etc. It is also important to note that the hypothesis presented here is incompatible with the metrical grid theory, given that allowing strong moras to occur outside of stressed syllables generates uncontinuous columns.

The constraints TROCHEE, IAMB and $\mu^{+} / \sigma$, as defined here, do not rule out quantityinsensitive iambs, which do exist in the Osage language (Altshuler 2009). Also, they offer an explanation for iambic lengthening of lexically bimoraic vowels (e.g., in St. Lawrence Island Yupik, see Hayes 1995: 241), and for languages in which lengthened short vowels are shorter than lexically long vowels (such as Chickasaw, see Gordon, Munro, Ladefoged 2002). At the same time, these constraints rule out iambs in which the initial syllable is lengthened.

\section{Optimality Theoretical analysis of Estonian quantity degrees with regard to weak and strong moras}

In Estonian, feet are disyllabic trochees regardless of the weight of their constituent syllables. Q3 is the only case in which a heavy syllable can form a foot of its own. In words that have relatively straightforward structures, the Q3 foot consists of a single syllable (Figure 22a), whereas in words with complex structures, the Q3 foot also has an unsyllabified mora (Figure 22b). 
The syllable that follows a monosyllabic foot is normally unparsed, which may explain the reduction of the unstressed vowel in Q3.

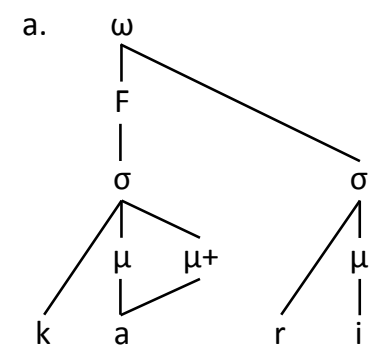

'arc, part.pl.' (Q3)

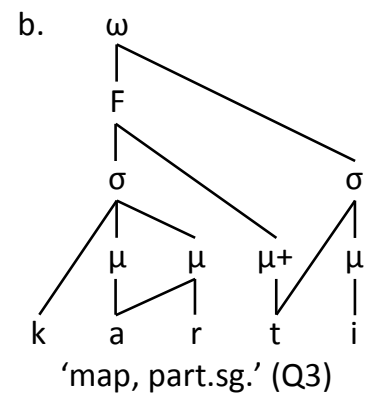

Figure 22 .

The foot-final mora may be lengthened to allow feet of differing segmental compositions to be pronounced with the same duration. Foot-final lengthening occurs when the constraint TROCHEE, which requires stress to fall on the foot-initial syllable, and the constraint IAMB, which requires the foot-final mora to be strong, are both satisfied. The need for the constraint PARSE- $\sigma$ becomes apparent for words with a long initial syllable. I assume that Estonian only allows strong moras at the end of syllables, feet or words.

PARSE- $\sigma \quad$ Syllables are parsed by feet (Kager 1999: 153).

\begin{tabular}{|c||c|c|}
\hline$/ k a_{\mu} \mathrm{lu}_{\mu} /$ 'fish, part.pl.' & TROCHEE & IAMB \\
\hline \hline$\left(\mathrm{ka}_{\mu} \cdot \mathrm{lu} \mathrm{u}_{\mu+}\right)$ & $* !$ & \\
\hline$\left(\mathrm{ká}_{\mu} \cdot \mathrm{lu} \mathrm{u}_{\mu}\right)$ & & $* !$ \\
\hline$\left(\mathrm{ká}_{\mu+} \cdot \mathrm{lu} \mathrm{u}_{\mu}\right)$ & & $* !$ \\
\hline$\left(\mathrm{ká}_{\mu} \cdot \mathrm{l} \mathrm{u}_{\mu+}\right)$ & & \\
\hline
\end{tabular}

Table 4.

\begin{tabular}{|c|c|c|c|}
\hline$/ \mathrm{ka}_{\mu \mu} \mathrm{lu}_{\mu} /$ 'weight, gen.sg.' & TROCHEE & IAMB & PARSE- $\sigma$ \\
\hline$\because \quad\left(k a_{\mu \mu} \cdot l_{\mu+}\right)$ & & & \\
\hline$\left(k a_{\mu \mu} \cdot \mid u_{\mu}\right)$ & & $* !$ & \\
\hline$\left(k a_{\mu \mu+}\right) \cdot l u_{\mu}$ & & & $* !$ \\
\hline
\end{tabular}

Table 5.

It is not quite clear whether CVC syllables in Estonian should be regarded as light or heavy. This issue is of secondary importance to the discussion of quantity degrees, which is the subject matter of this article, given that syllables containing a long vowel are heavy by all accounts and open syllables that have a short vowel are always light. CVC syllables can be analysed analogously with either of these types of syllables. Light CVC syllables do not require additional constraints at the top of the hierarchy, whereas heavy CVC syllables require a constraint that adds a mora to the syllable coda, known as CODA- $\mu$. To satisfy the constraint CODA- $\mu$, the coda may be linked to the same mora that the nucleus is linked to, i.e., the syllable can retain its light status. One option for blocking this mora sharing is *SHARED- $\mu$. All of the candidates listed in Table 6 have their codas linked to the moras (unless the coda consonant is followed by the subscript ' $\mu$ ', the coda shares the mora with the preceding segment). 
CODA $-\mu$ All coda consonants must be dominated by a mora (Broselow, Chen, Huffman 1997: 64).

*SHARED- $\mu$ Moras are linked to single segments (Broselow, Chen, Huffman 1997: 65).

DEP- $\mu \quad$ Every mora in the output has a correspondent in the input.

\begin{tabular}{|c|c|c|c|c|c|c|c|}
\hline $\begin{array}{l}/ \mathrm{pa}_{\mu} \mathrm{rve}_{\mu} / \\
\text { 'raft, gen.sg.' }\end{array}$ & CODA- $\mu$ & TROCHEE & IAMB & $*^{*} \sigma$-CLASH & PARSE- $\sigma$ & *SHARED- $\mu$ & DEP- $\mu$ \\
\hline (pá ${ }_{\mu}$ r.ve $\left.e_{\mu+}\right)$ & & & & & & *! & \\
\hline$\left(\right.$ pá $_{\mu+}$ r.ve $\left._{\mu}\right)$ & & & $* !$ & & & $*$ & \\
\hline$\left(p a_{\mu} r_{\mu} \cdot v e_{\mu+}\right)$ & & & & & & & $*$ \\
\hline$\left(\right.$ pá $\left._{\mu} r_{\mu+}\right) \cdot v e_{\mu}$ & & & & & $* !$ & & $*$ \\
\hline $\begin{array}{l}\text { 'pa }_{\mu} \text { rve }_{\mu}+l e_{\mu} / \\
\text { 'raft, all.sg.' }\end{array}$ & CODA- $\mu$ & TROCHEE & IAMB & ${ }^{*} \sigma-\mathrm{CLASH}$ & PARSE- $\sigma$ & *SHARED- $\mu$ & DEP- $\mu$ \\
\hline 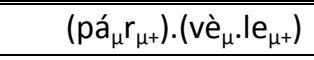 & & & & *! & & & * \\
\hline$\left(p a_{\mu} r_{\mu} \cdot v e_{\mu+}\right) \cdot l e_{\mu}$ & & & & & $*$ & & $*$ \\
\hline$\left(p a_{\mu} r_{\mu+}\right) \cdot v e_{\mu} \cdot e_{\mu}$ & & & & & $* * !$ & & $*$ \\
\hline
\end{tabular}

Table 6.

If the coda must be linked to a mora, if mora sharing is prohibited and if the last mora of the foot is strong, words like te.mal '(s)he, ad.sg.' should exhibit a word-final $l$ that is linked to a strong mora. This is obviously not the case, and one way to avoid this is the widely used constraint WSP, as shown in Table 7. For this hierarchy, unstressed CVC syllables are monomoraic. A detailed analysis of the stress system is beyond the scope of this article.

WSP Heavy syllables are stressed (Kager 1999: 155).

\begin{tabular}{|c|c|c|c|c|c|}
\hline$/ \mathrm{te}_{\mu} \mathrm{ma}_{\mu+} \mathrm{l} /$ & & IAMB & WSP & CODA- $\mu$ & *SHARED $-\mu$ \\
\hline (te. $\mathrm{m}$ & $\begin{array}{ll}\mu^{+} & \\
1 & \\
a & 1)\end{array}$ & & & $* !$ & \\
\hline (te. m & ${\stackrel{p^{+}}{\mu^{+}}}$ & & & & $*$ \\
\hline (te. $\mathrm{m}$ & $\begin{array}{ll}1 & 1 \\
a & 1\end{array}$ & $* !$ & * & & \\
\hline (te. m & $\begin{array}{ll}1 & 1 \\
a & 1\end{array}$ & & $* !$ & & \\
\hline
\end{tabular}

Table 7.

Q2 and Q3 cannot be determined by the segmental structure of a word. The example words Q2 kaa.lu and Q2 par.ve shown in the tables above can also be pronounced as Q3, which would change their meanings. The difference between Q2 and Q3 must therefore be lexical. While there are languages in which stress is a lexical phenomenon, in Estonian, mora strength is lexical. The presence of a strong mora in the input determines whether the output quantity degree of the word is Q3. This may represent a vestige of the stress system that predates the period of apocope and syncope, in which feet in output forms had a strong second mora (as is evident in the example from Finnish below, see Table 9). To preserve a lexically strong mora in the output forms, the constraint MAXLINK $-\mu^{+}$must be introduced at the top of the hierarchy. 
MAXLINK- $\mu^{+}$If a segment is linked to a strong mora in the input, that segment is also linked to a strong mora in the output.

For Q3 inputs, such as $/ \mathrm{pa}_{\mu} \mathrm{r}_{\mu+} \mathrm{ve}_{\mu} /$ 'raft, part.sg.', that have strong second moras, both syllables in the output cannot belong to the same foot as they do in a Q2 word composed of an identical sequence of segments, because, if this were allowed, the foot would exhibit two strong consecutive moras (violating the constraint ${ }^{*} \mu$-CLASH) or the lexically strong mora would have to be replaced with a weak one (violating the constraint MAXLINK- $\mu^{+}$), as shown in Table 8.

* $\mu$-ClaSH $\quad$ No stressed moras are adjacent (in a foot) (cf. Kager 1993: 393).

\begin{tabular}{|c|c|c|c|c|c|}
\hline$/ \mathrm{pa}_{\mu} \mathrm{r}_{\mu+} \mathrm{ve}_{\mu} /$ & 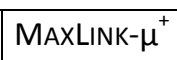 & TROCHEE & IAMB & ${ }^{*} \mu$-CLASH & PARSE- $\sigma$ \\
\hline 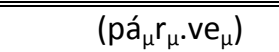 & $* !$ & & * & & \\
\hline$\left(p a_{\mu+} r \cdot v e_{\mu+}\right)$ & & & & $* !$ & \\
\hline$\left(p a_{\mu} r_{\mu+} \cdot v e_{\mu+}\right)$ & & & & $* !$ & \\
\hline$\left(\right.$ pá $\left._{\mu} r_{\mu} \cdot v e_{\mu+}\right)$ & $* !$ & & & & \\
\hline$\left(p a_{\mu} r_{\mu+}\right) \cdot v e_{\mu}$ & & & & & * \\
\hline
\end{tabular}

Table 8.

It is possible to induce a lengthening of the second mora, as in Finnish (see Suomi, Toivanen, Ylitalo 2003: 91), without a strong mora in the input. Finnish second mora lengthening is created when a constraint that prohibits sequences of weak moras is introduced at the top of the hierarchy, as follows:

* $\mu$-LAPSE No weak moras are adjacent (in a foot) (cf. RH-CONTOUR, Kager 1999: 174).

\begin{tabular}{|c|c|c|c|c|c|}
\hline$/ \mathrm{pa}_{\mu} \mathrm{rvi}_{\mu} /$ & ${ }^{*} \mu$-LAPSE & TROCHEE & ${ }^{*} \mu$-CLASH & PARSE- $\sigma$ & IAMB \\
\hline$\left(\right.$ pá $\left._{\mu} r_{\mu} \cdot v i_{\mu+}\right)$ & $* !$ & & & & \\
\hline$\left(p a_{\mu} r_{\mu+}\right) \cdot v i_{\mu}$ & & & & $* !$ & \\
\hline$\left(p a_{\mu} r_{\mu+} \cdot v i_{\mu}\right)$ & & & & & * \\
\hline$\left(p a_{\mu} r_{\mu+} \cdot v i_{\mu+}\right)$ & & & $* !$ & & \\
\hline$/ \mathrm{ka}_{\mu} \mathrm{Ia}_{\mu} /$ & ${ }^{*} \mu$-LAPSE & TROCHEE & ${ }^{*} \mu$-CLASH & PARSE- $\sigma$ & IAMB \\
\hline$\left(k a_{\mu} \cdot \mid a_{\mu}\right)$ & $* !$ & & & & $*$ \\
\hline$\left(k a_{\mu} \cdot l a_{\mu+}\right)$ & & & & & \\
\hline
\end{tabular}

Table 9.

It is more difficult to analyse words in which the initial syllable contains a long vowel and a geminate. For words in which changes in the quantity degree are induced morphologically, single stops alternate with geminates, e.g., Q2 kaar.di : Q3 kaa:rt.ti 'map, gen.sg. : part.sg.', Q2 uu.de : Q3 uu.t.te 'innovation, nom.sg. : gen.sg.'. The Q2 structure in which a long vowel is followed by a single stop does not warrant the conclusion that single stops are replaced by geminates in Q3, e.g., Q2 laa.di : Q3 laa:di 'style, gen.sg. : part.sg.' In addition to words containing a single stop, Q2 also allows words containing a geminate such as uut.te 'new, gen.pl.'. Because Q2 allows words that contain a single stop as well as those that contain a geminate, Q3 in corresponding structures cannot be interpreted simply as mora lengthening, as an additional mora linked to the stop is still 
needed. (The solution that posits that Q3 is always trimoraic would not simplify matters, as it requires that words be distinguished on the basis of whether their third mora is linked to a vowel, as in laa:di, or a stop, as in uu:t:te.) In addition to the MAXLINK- $\mu^{+}$, a separation between Q2 and Q3 in these words is facilitated by PARSE- $\mu$ and MAXLINK- $\mu(C)$.

MAXLINK- $\mu(C)$ When a consonant is linked to a mora in the input, it is also linked to a mora in the output, and when it is linked to two moras in the input, it is also linked to two moras in the output.

PARSE- $\mu \quad$ Moras are parsed by syllables.

The Q2 input $/ \mathrm{u}_{\mu \mu} \mathrm{te}_{\mu} /$ (uude) receives an output form that does not violate any high-ranked constraints (Table 10A). In the Q3 input $/ \mathrm{u}_{\mu \mu+} \mathrm{t}_{\mu} \mathrm{e}_{\mu} /$ (uu:t:te), however, it is impossible to retain all of the moras as they would remain unparsed. At the same time, it is impossible to accommodate all of the moras in the same foot, given that this would violate the constraint * $\mu$-CLASH or higher-ranking constraints, as shown in Table 10B. These problems do not arise with the Q2 input $/ \mathrm{u}_{\mu \mu} \mathrm{t}_{\mu} \mathrm{e}_{\mu} /$ (uutte), because it does not have a strong mora, as shown in Table 10C. The output form corresponding to the input $/ \mathrm{u}_{\mu \mu} \mathrm{t}_{\mu+} \mathrm{e}_{\mu} /$ would be the candidate $a$ in Table 10B. It is remarkable that both possible Q3 outputs have lengthened both $u$ and $t$ when compared to the Q2 form uutte. This explains why alternations, such as uut.te : uu:t.te vs. uut.te : uut:.te (see the blanks in Figure 21), do not exist.

Now it is easy to establish that in the case of the $\mathrm{Q} 2$ input $/ \mathrm{ka}_{\mu \mu} \mathrm{rt} \mathrm{i}_{\mu} /$ (kaardi 'map, gen.sg.') the output is the structure shown in Figure 23. Of more interest is what happens to the inputs for $\mathrm{Q} 2 / \mathrm{ka}_{\mu \mu} \mathrm{rt}_{\mu} \mathrm{e}_{\mu} /$ (kaartte 'arc, gen.pl.') and $\mathrm{Q} 3 / \mathrm{ka}_{\mu \mu} \mathrm{rt}_{\mu+} \mathrm{e}_{\mu} /$ (kaa:rt:te 'map, part.pl.'), as shown in Table 11. In Estonian, Q2 words that have the sequence CVVNT.TV are only possible in exceptional cases when the morphological marker -tte is added to a stem that ends in a sonorant. The hierarchy of constraints that has been used in the analysis so far leads to the selection of a candidate that has three different segments linked to the same mora (Table 11A, candidate $\mathrm{c}$ ) as the output form for Q2 $/ \mathrm{ka}_{\mu \mu} \mathrm{rt}_{\mu} \mathrm{e}_{\mu} /$. The output form that corresponds to the Q3 input $/ \mathrm{ka}_{\mu \mu} \mathrm{rt}_{\mu+} \mathrm{e}_{\mu} /$ contains a mora that is not linked to the syllable node, as this is the only way to retain the link between /t/ and a strong mora without violating more important constraints.

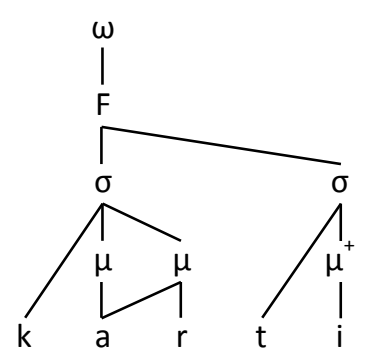

Figure 23 . 


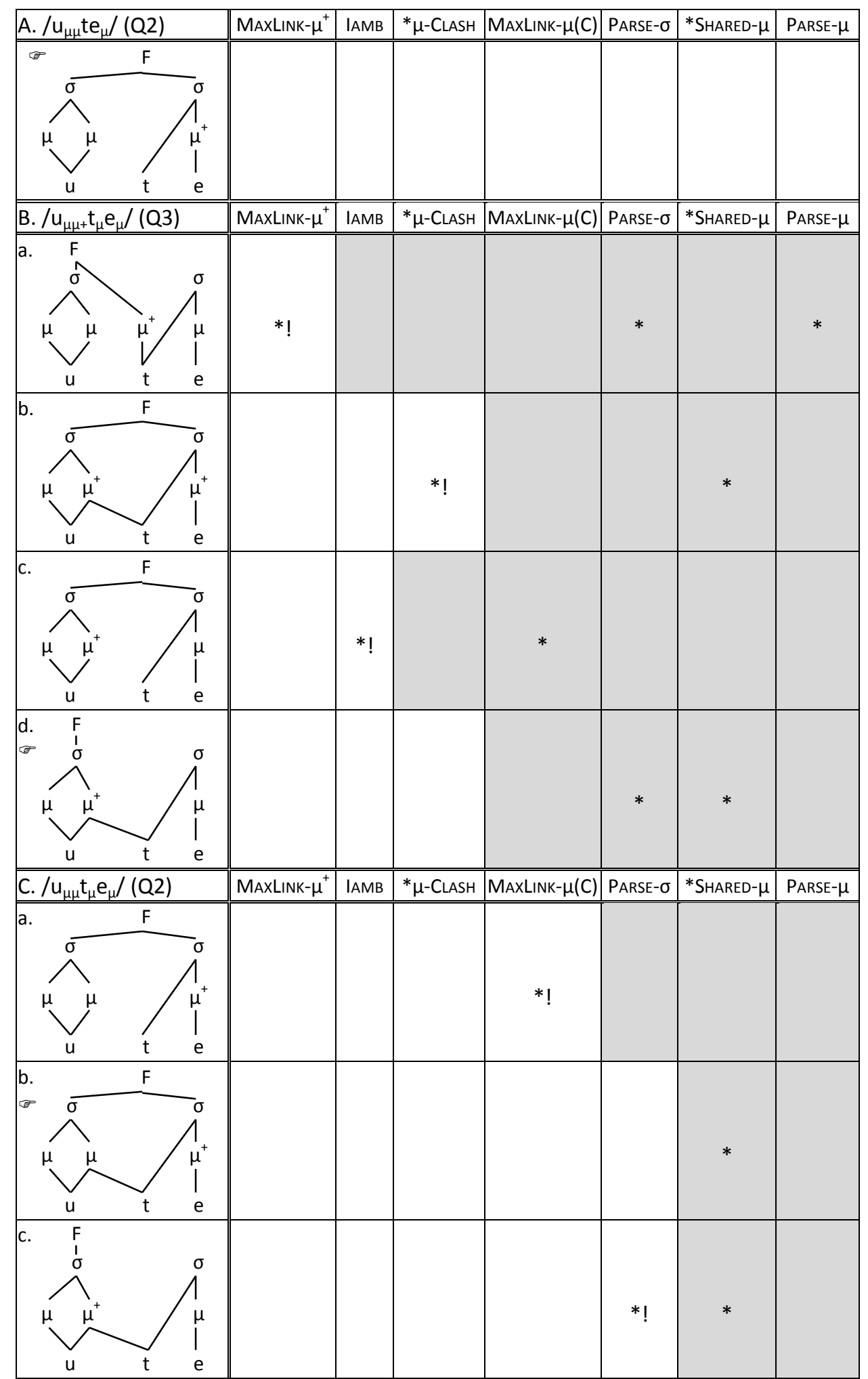

Table 10. 


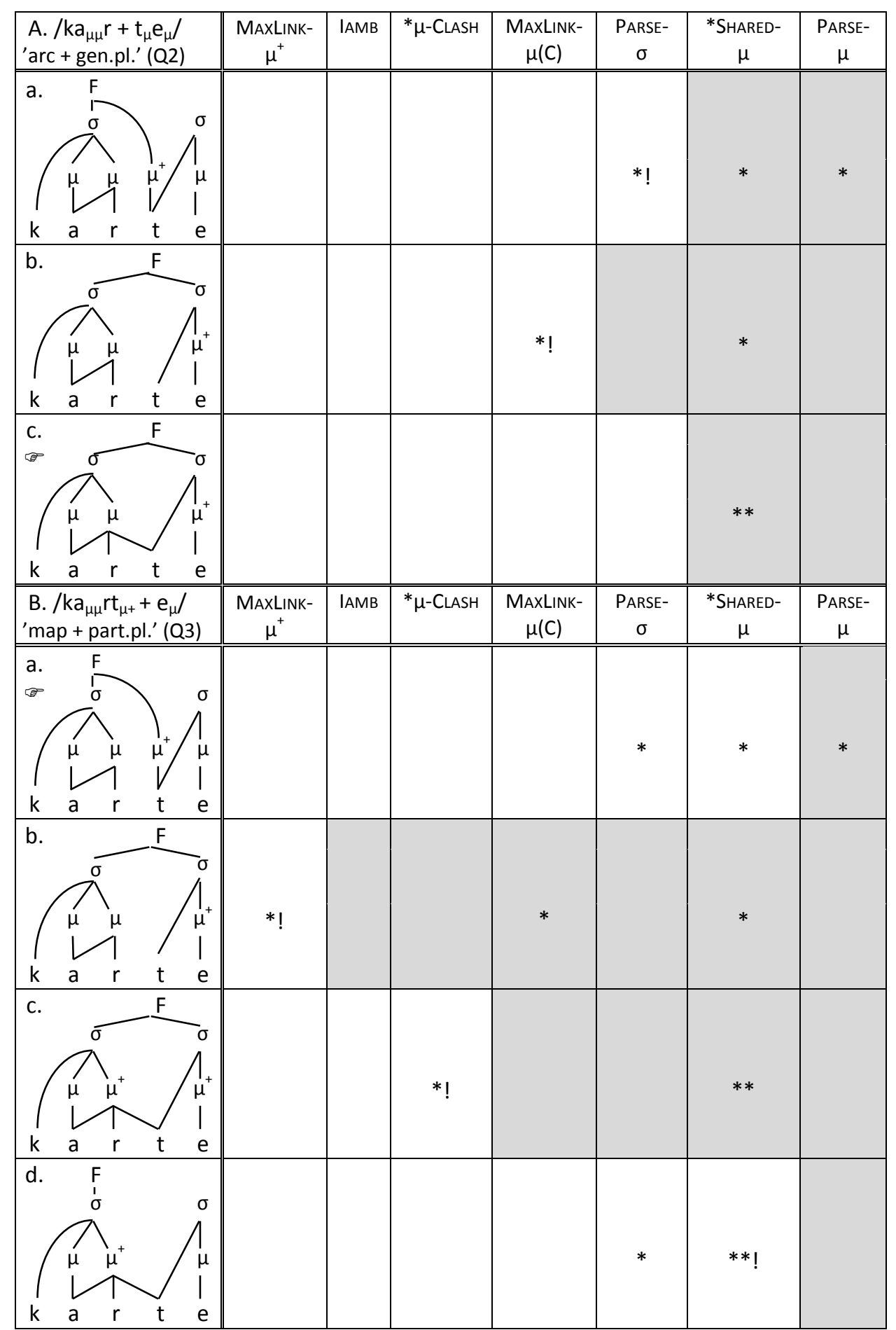

Table 11 .

When the phonetic durations of the sounds in the Q2 word kaart.te and in the Q3 word kaa:rt:te are compared, the $t$ in the Q3 form should be significantly longer than in the Q2 one (1/3 mora vs. strong mora), whereas the $a$ and $r$ in both forms should have approximately the same duration. Phonetic measurements should make it possible to verify whether this solution fits or whether a different one must be formulated. Conceivable alternatives are a ternary branching mora in Q3, a nonmoraic geminate in Q2 or mora sharing between syllable onset and the nucleus in Q2.

The previous tables allow to compare the explanations of overlength as foot-final lengthening. If foot-final lengthening means the addition of a mora, the initial syllables of kaa:rt:te 
and $u u: d e$ (or rather, the corresponding initial syllable plus the extrasyllabic mora following it), as well as the monosyllabic words maa: 'land' and maa:st 'land, elat.sg.', should all be trimoraic. When strong moras are used, the initial Q3 syllables and Q3 monosyllabic words should be either bimoraic or trimoraic depending on their segmental composition. Another difference is that the additional mora is not set at the end of a Q2 foot, whereas a strong mora must, given the IAMB constraint, exist at the end of a Q2 foot. A strong mora does not mean a stable phonetic lengthening. A strong mora at the end of a foot is in consonance with the fact that an overlong vowel is not three times longer than a short vowel; rather, it is less than two and a half times longer (the long vowel is about twice as long as the short vowel, see Lippus et al. 2013). Finally, a clarification of how to provide an account of the Seto foot-final gemination is needed. One option is to posit that strong moras are preferably branching.

I sum, the hierarchy of constraints describing the Estonian quantity degrees with weak and strong moras is the following:

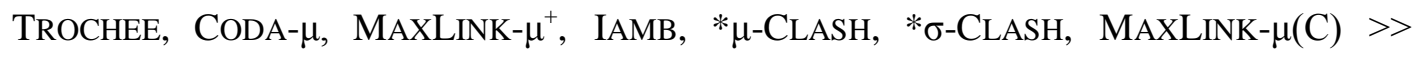
PARSE- $\sigma>>$ *SHARED $\mu$ > PARSE- $\mu$

\section{Conclusions}

Phonological accounts of Estonian quantity degrees have aroused the interest of many researchers and provided a stimulus for developing phonological theory. The Estonian language possesses a unique feature in that it admits a three-way length opposition in vowels and consonants. This feature makes it difficult to subject Estonian quantity degrees to the methods of analysis that have been used with other languages that exhibit ternary length opposition.

The simplest option would be to say that a Q1 syllable has one mora, a Q2 syllable has two moras and a Q3 syllable has three moras. However, when we assume that phonological constituents are maximally binary and that weak layering, although permitted, only allows one level to be skipped, it follows that so-called three-moraic syllables are really binary feet that consist of a syllable and a mora that are directly linked to the foot node.

Overlong segments arise due to foot-final lengthening in monosyllabic feet. Because of foot-final lengthening, the Q3 syllable as a separate foot is longer than the initial syllable of a Q2 foot. Previous accounts of final lengthening have treated this as a purely phonetic phenomenon. Yet, this raises considerable difficulties with regard to explaining how foot-final lengthening can be realised via gemination of $h$ in Seto Estonian or why foot-final lengthening is not observed in all languages. Final lengthening may be interpreted as the addition of a mora, as suggested by Paul Kiparsky and Karl Pajusalu (in preparation), yet it may also be regarded as a strong mora. In the last chapters of this article, I modified René Kager's (1993) theory of weak and strong moras, expanding on the possible locations that strong moras can occupy in the syllable and in the foot. This approach links foot-final lengthening to iambic stress systems, which also extend the length of the second syllable of a foot. 
The proposed approach to Estonian quantity degrees is in consonance with the following phonetic facts. First, the reduction of a vowel in an unstressed syllable following a Q3 foot results from the fact that this syllable is unparsed by a foot. Second, the overlong vowel that is linked to one weak mora and one strong mora is phonetically about 2.5 times as long as a short (monomoraic) vowel. A regular bimoraic vowel is twice as long as a monomoraic one. A strong mora does not always lead to stable phonetic lengthening, which is a consequence that the addition of a mora is likely to produce. Third, monosyllabic CVV words may be bimoraic and thus are phonetically shorter than CVVCC words.

\section{References}

Altshuler, D. 2009, Quantity Insensitive Iambs in Osage. - International Journal of American Linguistics, 365-398.

Andersen, T. 1992-1994, Morphological Stratification in Dinka: On the Alternations of Voice Quality, Vowel Length and Tone in the Morphology of Transitive Verbal Roots in a Monosyllabic Language. - Studies in African Linguistics, 1-63.

Ariste, P. 1953, Eesti keele foneetika, Tartu.

Asu, E. L., Teras, P. 2009, Illustrations of the IPA: Estonian. - Journal of the International Phonetic Association, 367-372.

Broselow, E., Chen, S., Huffman, M. 1997, Syllable Weight: Convergence of Phonology and Phonetics. Phonology, 47-82.

Bye, P. 1997, A Generative Perspective on 'Overlength' in Estonian and Saami. - Estonian Prosody: Papers from a Symposium. Proceedings of the International symposium on Estonian Prosody, Tallinn, Estonia, October 29-30, 1996, Tallinn, 36-70.

Bye, P., Sagulin, E., Toivonen, I. 2009, Phonetic Duration, Phonological Quantity and Prosodic Structure in Inari Saami. - Phonetica, 199-221.

Crowhurst, M. J. 1996, An Optimal Alternative to Conflation. - Phonology, 409-424.

Davis, S. 2003, The Controversy over Geminates and Syllable Weight. - Syllable in Optimality theory, Cambridge, 77-98.

Eek, A. 2008, Eesti keele foneetika, Tallinn.

Eek, A., Meister, E. 1998, Quality of Standard Estonian Vowels in Stressed and Unstressed Syllables of the feet in Three distinctive Quantity Degrees. - LU XXXIV, 226-233.

Eek, A., Meister, E. 2003, Foneetilisi katseid ja arutlusi kvantiteedi alat (I). Häälikukestusi muutvad kontekstid ja välde. - KK, 815-837, 904-918.

Eek, A., Meister, E. 2004, Foneetilisi katseid ja arutlusi kvantiteedi alalt (II). Takt, silp ja välde. - KK, 251271, 336-357.

Ehala, M. 1999, Eesti väldete probleemi üks lahendusi. - KK, 378-386, 453-466.

Ehala, M. 2003, Estonian Quantity: Implications for Moraic Theory. - Generative Approaches to Finnic and Saami Linguistics, Stanford, 51-80.

Fox, R. A., Lehiste, I. 1989, Discrimination of Duration Ratios in Bisyllabic Tokens by Native English and Estonian Listeners. - Journal of Phonetics, 167-174. 
Gordon, M., Munro, P., Ladefoged, P. 2002, Chickasaw. - Journal of the International Phonetic Association, 287-290.

Gussenhoven, C. 2009, Vowel Duration, Syllable Quantity, and Stress in Dutch. - The Nature of the Word. Studies in Honor of Paul Kiparsky, Cambridge, 181-198.

Gussenhoven, C., Peters, J. 2004, A Tonal Analysis of Cologne Schärfung. - Phonology, 251-285.

Hallap, V. 1962, Mõtteid eesti keele väldete foneetika kohta. - Emakeele Seltsi Aastaraamat VIII, $238-250$.

Hayes, B. 1989, Compensatory Lengthening in Moraic Phonology. - Linguistic Inquiry, 253-306.

Hayes, B. 1995, Metrical Stress Theory, Chicago, London.

Hint, M. 1997, Eesti keele astmevahelduse ja prosoodiasüsteemi tüpoloogilised probleemid, Tallinn, Helsinki.

Hint, M. 1998, Häälikutest sõnadeni. Eesti keele häälikusüsteem üldkeeleteaduslikul taustal. Teine, ümbertöötatud trükk, Tallinn.

Hint, M. 2001, Prosoodiaväitluses läbimurdeta. - KK, 164-172, 252-258, 324-339.

Hyman, L. M. 1985. A Theory of Phonological Weight, Dordrecht.

Ito, J., Mester, A. 2003, Weak Layering and Word Binarity. - A New Century of Phonology and Phonological Theory. A Festschrift for Professor Shosuke Haraguchi on the Occasion of His Sixtieth Birthday, 26-65.

Kager, R. 1992, Shapes of the Generalized Trochee. - The Proceedings of the Eleventh West Coast Conference on Formal Linguistics, Chicago, 298-312.

Kager, R. 1993, Alternatives to the Iambic-Trochaic Law. - Natural Language \& Linguistic Theory, 381432.

Kager, R. 1997, Generalized Alignment and Morphological Parsing. - Rivista di Linguistica, 245-282.

Kager, R. 1999, Optimality Theory, Cambridge.

Kiparsky, P. 2003, Syllables and Moras in Arabic. - Syllable in Optimality Theory, Cambridge, 147-182.

Kiparsky, P., Pajusalu, K. (in preparation), Seto Vowel Harmony and The Typology of Disharmony. <www.stanford.edu/ kiparsky/Papers/seto.pdf>

Kohler, K. J. 2001, Überlänge im Niederdeutschen? - Festschrift für Hubertus Menke zum 60. Geburtstag, Heidelberg, 385-402.

Lahiri, A., Koreman, J. 1988, Syllable Quantity and Stress in Dutch. - Proceedings of the West Coast Conference on Formal Linguistics, VII, 217-228.

Lehiste, I. 1960, Segmental and Syllabic Quantity in Estonian. - American Studies in Uralic Languages I, 21-82.

Lehiste, I. 1965, The Function of Quantity in Finnish and Estonian. - Language, 447-456.

Lehiste, I. 2003, Prosodic Change in Progress: From Quantity Language to Accent. - Development in Prosodic Systems, Berlin, New York, 47-65.

Liiv, G. 1961. Eesti keele kolme vältusastme vokaalide kestus ja meloodiatüübid. - KK, 412-424, 480-490.

Lippus, P. 2010, Variation in Vowel Quality as a Feature of Estonian Quantity. - Speech Prosody 2010, Chicago.

Lippus, P., Asu, E. L., Teras, P., Tuisk, T. 2013, Quantity-Related Variation of Duration, Pitch and Vowel Quality in Spontaneous Estonian. - Journal of Phonetics, 17-28. 
Lippus, P., Pajusalu, K., Allik, J. 2007, The Tonal Component in Perception of the Estonian Quantity. - The Proceedings of the 16th International Congress of Phonetic Sciences: 16th International Congress of Phonetic Sciences, Saarbrücken, Germany, 6-10 August 2007, 1049-1052.

Lippus, P., Pajusalu, K., Allik, J. 2009, The Tonal component of Estonian Quantity in Native and Non-native Perception. - Journal of Phonetics 37, 388-396.

Lippus, P., Pajusalu, K., Teras, P. 2006, The Temporal Structure of Penta- and Hexasyllabic Words in Estonian. - Proceedings of Speech Prosody. 3rd International Conference, Dresden, May 2-5, 2006, Dresden, 759-762.

Maddieson, I. 1993, Splitting the Mora. - UCLA Working Papers in Phonetics 83, California, 9-18.

McCarthy, J. J. 1986, OCP Effects: Gemination and Antigemination. - Linguistic Inquiry, 207-263.

McCarthy, J. J, Prince, A. 1996, Prosodic Morphology 1986. - Technical Report \#32, Rutgers University Center for Cognitive Science.

Nespor, M., Vogel, I. 1986, Prosodic Phonology, Foris, Dordrecht.

Pajusalu, K. 2002, . Varieerumisreeglid ja optimaalsusteooria. - Teoreetiline keeleteadus Eestis, Tartu, 195208.

Pajusalu, K., Help, T., Lippus, P., Niit, E., Teras, P., Viitso, T.-R. 2005, On the Temporal Structure of Estonian Secondary-Stressed Feet. - LU XLI, 98-106.

Prince, A. 1980, A Metrical theory for Estonian Quantity. - Linguistic Inquiry, 511-562.

Prince, A., Smolensky, P. 2004, Optimality Theory: Constraint Interaction in Generative Grammar, Malden, MA.

Remijsen, B., Gilley, L. 2008, Why are Three-level Vowel Length Systems Rare? Insights from Dinka (Luanyjang dialect). - Journal of Phonetics, 318-344.

Rolle, N. 2009, The Phonetic Nature of Niuean Vowel Length. - Toronto Working Papers in Linguistics (TWPL), 1-19.

Selkirk, E. O. 1984, Phonology and Syntax: The Relation between Sound and Structure. Cambridge, MA, London.

Smith, N. 2004, Vowel Length in Applecross Gaelic. - Words in Their Places: a Festschrift for J. Lachlan Mackenzie, Amsterdam, 293-298.

Suomi, K., Toivanen, J., Ylitalo, R. 2003, Durational and Tonal Correlates of Accent in Finnish. - Journal of Phonetics, 113-138.

Suomi, K., Meister, E., Ylitalo, R., Meister, L. 2013, Durational Patterns in Northern Estonian and Northern Finnish. - Journal of Phonetics, 1-16.

Zec, D. 2007, The Syllable. - The Cambridge Handbook of Phonology, Cambridge, 161-194.

Ternes, E. 1989, The Phonemic Analysis of Scottish Gaelic: Based on the Dialect of Applecross, Ross-shire, Hamburg.

Vaux, B., Wolfe, A. 2009, The Appendix. - Contemporary Views on Architecture and Representations in Phonology, 101-143.

Viitso, T.-R. 1981, Läänemeresoome fonoloogia küsimusi, Tallinn. 
Viitso, T.-R. 1997, The Prosodic System of Estonian in the Finnic Space. - Estonian Prosody: Papers from a Symposium. Proceedings of the International Symposium on Estonian Prosody, Tallinn, Estonia, October 29-30, 1996, Tallinn, 222-233.

Viitso, T.-R. 2008, Liivi keel ja läänemeresoome keelemaastikud, Tartu, Tallinn.

Võrk, L. 1966, Viron kielen ääntämys, Jyväskylä.

Watson, J. C. 2007, Syllabification Patterns in Arabic Dialects: Long Segments and Mora Sharing. Phonology, 335-356. 